\title{
Article \\ Comparative Analysis of the Indirect Calorimetry and the Metabolic Power Method to Calculate Energy Expenditure in Team Handball
}

\author{
Patrick Fuchs $^{1, *(1)}$, Live S. Luteberget ${ }^{2}{ }^{(}$, Philip X. Fuchs ${ }^{3}\left[\right.$ and Herbert Wagner ${ }^{1}(\mathbb{D}$ \\ 1 Department of Sport and Exercise Science, University of Salzburg, Hallein, 5400 Salzburg, Austria; \\ herbert.wagner@sbg.ac.at \\ 2 Department of Physical Performance, Norwegian School of Sports Sciences, 0863 Oslo, Norway; livesl@nih.no \\ 3 Department of Athletic Performance, National Taiwan Normal University, Taipei 116, Taiwan; \\ philip.fuchs@ntnu.edu.tw \\ * Correspondence: patrick.s.fuchs@gmx.de
}

check for updates

Citation: Fuchs, P.; Luteberget, L.S.; Fuchs, P.X.; Wagner, H. Comparative Analysis of the Indirect Calorimetry and the Metabolic Power Methodto Calculate Energy Expenditure in Team Handball. Appl. Sci. 2022, 12, 163. https://doi.org/10.3390/ app12010163

Academic Editor: Christian W. Dawson

Received: 22 November 2021 Accepted: 22 December 2021 Published: 24 December 2021

Publisher's Note: MDPI stays neutral with regard to jurisdictional claims in published maps and institutional affiliations.

Copyright: (C) 2021 by the authors. Licensee MDPI, Basel, Switzerland. This article is an open access article distributed under the terms and conditions of the Creative Commons Attribution (CC BY) license (https:// creativecommons.org/licenses/by/ $4.0 /)$.

\begin{abstract}
Monitoring physical activity, e.g., training load and energy expenditure (EE), is important to optimize the training process in various sports. Especially in team handball, where there is little information about EE in training and competition. The objective of the study was to compare EE in team handball derived from a respiratory gas exchange analysis (spiroergometry) and a local position measurement (LPM) system. Eleven participants completed a validated, team handball game-based performance test and wore a portable spiroergometry system (K5 Cosmed) and an LPM transponder (Catapult ClearSky T6). EE was determined via indirect calorimetry for spiroergometry data and via the metabolic power model for EE for LPM data. EE estimated via the metabolic power model was -66 to $-63 \pm 12 \%$ lower than via indirect calorimetry $\left(p<0.001, \mathrm{p} \eta^{2}=0.97\right)$. No correlation was found for the overall test $(r=0.32, p=0.34)$, nor for every single heat $(r \leq 0.44$, $0.18 \leq p \leq 0.99$ ). Therefore, regression analyses predicting spiroergometry data based on LPM data were not feasible. In line with previous studies, the metabolic power model for EE in team handball (including short-distance movements, great accelerations, and non-locomotive actions) is not suitable.
\end{abstract}

Keywords: respiratory gas exchange analysis system; local position measurement system; specific performance testing; oxygen uptake

\section{Introduction}

Monitoring physical activity, e.g., training load and energy expenditure (EE), is important to optimize the training process in various sports [1-3]. Knowledge about EE allows for adaptations of training sessions and structures according to sport-specific demands in training and competition. To our best knowledge, EE is mainly used for monitoring cyclical movements (running, cycling, XC skiing) because these movements are easily imitable under laboratory conditions. For example, $\mathrm{EE}$ has been obtained via indirect calorimetry $\left(\mathrm{EE}_{\text {Spiro }}\right)$, often considered as the gold standard for the calculation of EE, to compare the effects of different shoe materials during running [4]. $\mathrm{E}_{\text {Spiro }}$ analyses has also been applied in cycling to assess the metabolism on an energy and exergy basis [5]. In sports that are based on acyclic movements (e.g., team sports), the assessment of EE is controversially discussed, and spiroergometry is often unfeasible in competition and/or training [6]. Studies on EE in team sports collected respiratory data based on movements that may be common in general but not appropriately reflect the sport-specific demands $[7,8]$. Due to this deficit, the metabolic power model of EE determined by local position measuring (LPM) data was developed [9]. The strength of this method is its applicability in competition because EE $\left(\mathrm{EE}_{\mathrm{LPM}}\right)$ can be determined via an LPM system, and no spiroergometry system is necessary to estimate EE. The calculation of $\mathrm{EE}_{\mathrm{LPM}}$ is based on the translation of tilt angles between the ground and the center of mass during accelerated flat running to incline angles during 
constant uphill running, for which EE is known [10]. Spiroergometry and LPM data were collected simultaneously in soccer [11,12] and rugby [13] to compare the two methods of EE determination in team sports. An underestimation of $E_{L P M}$ compared to $E_{S p i r o}$ was found when performing sport-specific movements [11-13]. One explanation is that LPM usually measures only horizontal position data, which do not reflect EE for specific movements like collisions, jumps, passes, and shots; thus, the demand for such actions is not considered properly in LPM data [12,13].

Team sports like team handball are very complex and characterized by multiple sportspecific movements like accelerations, decelerations, change of directions, jumps, passes, throws, and tackles in offense and defense [14-17]. A systematic comparison of EE $E_{\mathrm{LPM}}$ and $\mathrm{EE}_{\text {Spiro }}$ determination in team handball should therefore include these specific movements in the test protocol [18]. We expected a systematic underestimation of EE LPM $_{\text {also in team }}$ handball, as shown previously [11-13]. However, this supposed underestimation of $\mathrm{EE}_{\mathrm{LPM}}$ does not exclude a possible significant correlation between both methods in EE if the difference is systematic. It represents a remarkable chance to advance the application of EE in team sports and was never investigated in previous studies. A systematic correlation between $\mathrm{EE}_{\mathrm{LPM}}$ and $\mathrm{EE}_{\text {Spiro }}$ would enable the development of a regression model to predict valid $\mathrm{EE}_{\text {Spiro }}$ (the gold standard method) based on LPM data. Consequently, EE could be determined accurately without limitation in training and competition. The game-based performance test (GBPT), was specifically developed and validated for team handball, including the team handball specific movements, durations, and intensities, as well as physiological and perceptional effects measured during competition [19]. Therefore, the GBPT reflects the EE demands in team handball and, in contrast to team handball training or competition, allows for spiroergometry measurement. Consequently, the GBPT is suitable to determine valid $\mathrm{EE}$ in team handball and to compare $\mathrm{EE}_{\mathrm{LPM}}$ and $\mathrm{EE}_{\text {Spiro. }}$.

In addition to the systematic bias due to sport-specific movements, the EE during rest (no change of position) represents another systematic error between $E_{\text {LPM }}$ and $E_{\text {Spiro }}$ due to the different considerations of internal or organic processes. It was suggested to subtract the resting energy expenditure (REE) [20] from the gross $E_{\text {Spiro }}$; the alleged [21] lack of this subtraction in a previous study [12] was already criticized [22]. However, as the $E_{L P M}$ considers only locomotion data, the subtraction of EE in standing position in a pre-activated rest might be appropriate for a comparison between $\mathrm{EE}_{\mathrm{LPM}}$ and $\mathrm{EE}_{\text {Spiro }}$. Such EE in a pre-activated, motionless rest may be affected by the excess post-exercise oxygen consumption (EPOC) [23]. Thus, in addition to uncertainties about the precision of EPOC determination and the uncertainty of whether to subtract it or not [24], the use of such EE in a pre-activated, motionless rest is unclear. Consequently, the EE in a pre-activated, motionless rest in team handball should be determined separately to demonstrate if a subtraction of EE (REE or pre-activated, motionless EE) from the gross $E_{\text {Spiro }}$ is necessary to determine the $\mathrm{EE}_{\mathrm{LPM}}$ accurately. To our best knowledge, neither the EE in team handball in competition-like conditions nor the comparison of $\mathrm{EE}_{\mathrm{LPM}}$ and $\mathrm{EE}_{\text {Spiro }}$ in team handball have been investigated.

Therefore, the objectives of the study were (1) to analyze the difference between $\mathrm{EE}_{\text {Spiro }}$ and $\mathrm{EE}_{\mathrm{LPM}}$ in the team handball GBPT, (2) to investigate the correlation between $\mathrm{EE}_{\text {Spiro }}$ and $E_{\mathrm{LPM}}$, (3) to develop a regression model that predicts $\mathrm{EE}_{\text {Spiro }}$ based on $\mathrm{EE}_{\mathrm{LPM}}$, and (4) to compare REE with EE during a pre-activated motionless rest in team handball. We hypothesized that (1) $\mathrm{EE}_{\text {Spiro }}$ would be higher compared to $\mathrm{EE}_{\mathrm{LPM}},(2)$ that $\mathrm{E}_{\text {Spiro }}$ and $E_{\text {LPM }}$ show a systematic correlation, (3) which allows for developing a regression model to predict $\mathrm{EE}_{\text {Spiro }}$ based on $\mathrm{EE}_{\mathrm{LPM}}$ and (4) that REE underestimates the relevant EE, whereas EE in a pre-activated, motionless rest will be overestimated.

\section{Materials and Methods}

\subsection{Participants}

Eleven male $(n=6)$ and female $(n=5)$ experienced team handball players (mean \pm SD for age: $25 \pm 8$ years; body height: $1.75 \pm 0.09 \mathrm{~m}$; body mass: $76.7 \pm 9.4 \mathrm{~kg}$; eight right 
and three left-handed players) from the first $(n=3)$, second $(n=4)$, and third $(n=4)$ Norwegian Handball League participated in the present study. G*Power 3.1 (Heinrich Heine University, Düsseldorf, Germany) analyses showed that the current sample size resulted in $80 \%$ likelihood to detect large effects at $p<0.05$. All participants were healthy, in good physical condition, and reported no injuries during the time of study implementation. The local ethics committee approved the study in accordance with the Declaration of Helsinki. All participants agreed and signed informed consent.

\subsection{Study Design}

Two different measuring systems (spiroergometry and LPM) collected data simultaneously to compare the calculation of $\mathrm{EE}_{\text {Spiro }}$ and $\mathrm{EE}_{\mathrm{LPM}}$ in the team handball GBPT (testing protocol). Before starting the GBPT, all participants were familiarized with the testing procedure by the test administrator (theoretical familiarization). To optimize test efficiency, four players were involved at the same time, where one performed the test, two were used as passing partners during the test, and the fourth was warming up for the following test. The warm-up consisted of a 20 min general and specific warm-up, similar to that used in competition. After the warm-up the measuring equipment was attached to the athlete, all systems were calibrated and started simultaneously. After a countdown of two minutes, the athlete performed a specific warm-up heat in the GBPT (practical familiarization) including only submaximal movements of the test.

\subsection{Game-Based Performance Test}

The GBPT consists of eight heats including defense, defense to offense, offense, offense to defense, and active breaks (see Figure 1). During defensive actions, the athletes had to tackle padded roll mats, one central at $6 \mathrm{~m}$, two at the left and right backcourt positions at $9 \mathrm{~m}$, which created a triangle (starting central, tackling twice left side, one time right side for right-handed players, and vice versa for left-handed players).

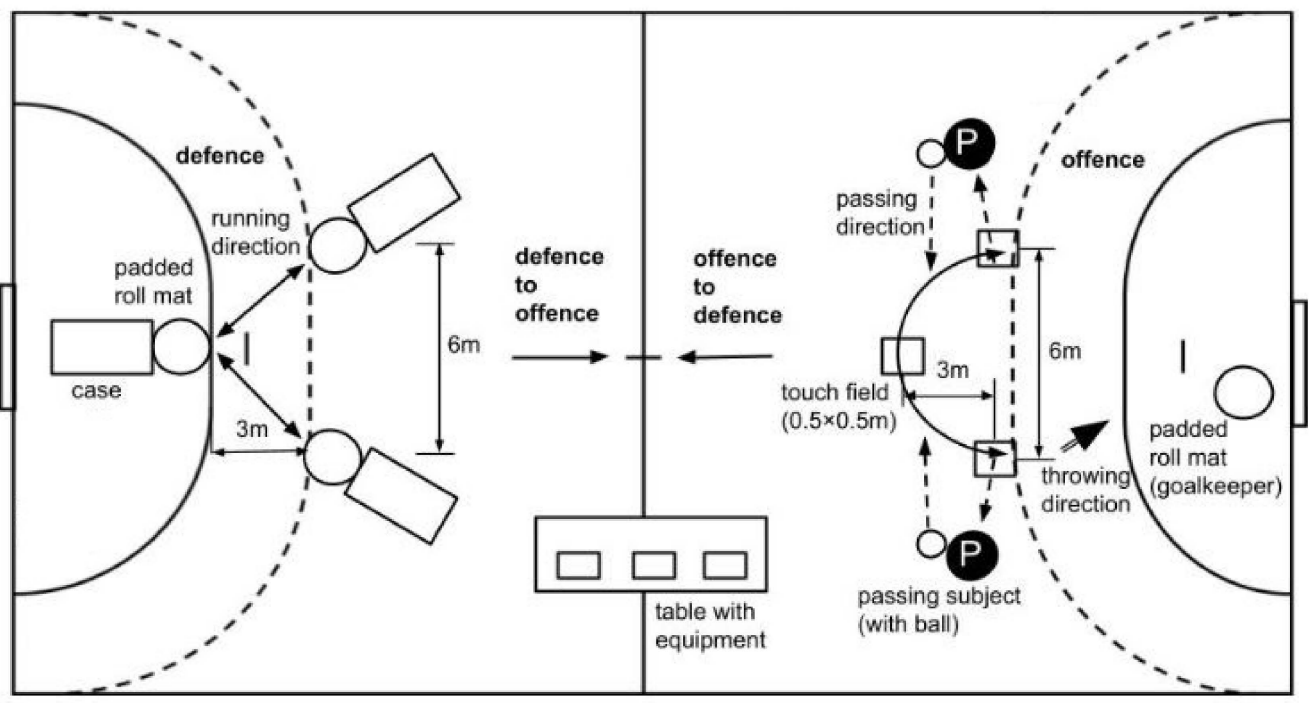

Figure 1. Schematic diagram of the team handball specific game-based performance test (GBPT) including measuring and testing equipment [19].

In offense, the athletes had to catch and pass the ball during sprinting between the $9 \mathrm{~m}$ line and $12 \mathrm{~m}$, where they had to touch $0.5 \times 0.5 \mathrm{~m}$ touching fields on the floor (starting at $12 \mathrm{~m}$, finishing at the $9 \mathrm{~m}$ line, twice right side, one time left side for right-handed players, and vice versa for left-handed players). In five out of eight heats, players had to finish the offense action with a jump shot, throwing as fast as possible to the lower-left corner of the goal after maximal take-off from the left foot (for right-handed players, and vice versa for left-handed players). In heat 3 and 6, the players had to sprint from defense to offense, 
finishing with a jump shot (fast break), while in heat 4 and 6 they had to sprint from offense to defense (running back). Players were instructed to jump and throw as high and as fast as possible and to sprint and move as fast as possible in both defense and offense. The number of activity changes, changes in direction, shots, passes, and tackles were selected from studies that analyzed matches in elite male and female team handball [15-17,25-27]. All distances during these actions were standardized by markers on the court or the positions of the padded roll mats (see Figure 1). Breaks (15 s between two defense or offense actions, $20 \mathrm{~s}$ between defense and offense and vice versa, and $20+40$ s between the single heats) were controlled by the Multi-Timer-Ultimate software (Multi-Timer-Ultimate 3.1, Wallroth, Berlin, Germany). These specific actions were selected to simulate the specific physical performance in team handball competition. A detailed description of the game-based performance test and the determination of validity and test-retest reliability was reported in separate studies $[19,28]$.

\subsection{Testing Methods}

During the GBPT, two systems were used to calculate EE [kJ/ kg/min] for the entire test as well as for every single heat. For comparability with previously published reference values, EE was additionally presented as $\mathrm{kJ} / \mathrm{min}$.

Oxygen uptake $\left(\mathrm{VO}_{2}\right)$ was measured via a portable respiratory gas exchange analysis system in breath-by-breath mode (K5, Cosmed, Rome, Italy) [29,30]. EE Spiro was calculated using the $\mathrm{VO}_{2}$ and the respiratory quotient following the standards of indirect calorimetry [31]. REE was adopted from existing literature [32] and normalized on individual body mass. For consideration of EE in a pre-activated, motionless state, EE was determined during breaks of $40 \mathrm{~s}$ between all heats, in which the participants were standing still and waiting for starting the next heat. Only those breaks were used, where the total distance obtained via LPM was less than $10 \mathrm{~m}$ within the $40 \mathrm{~s}$.

LPM system (Catapult ClearSky, Catapult Sports, Melbourne, Australia) tracked the position during the GBPT [33,34]. A transponder (Catapult ClearSkyT6, firmware ver. 5.6), worn in a supplied harness on the upper back, transmitted data to a base station at $10 \mathrm{~Hz}$ sample frequency. Horizontal positions, velocity, and acceleration were calculated via the manufacturer's computer software (Catapult OpenField ver. 1.17.2). Subsequently, the metabolic power model provided by di Prampero et al. [9] was applied to estimate $E_{\mathrm{LPM}}$ based on acceleration data. For this method, acceleration and deceleration during flat running are translated into equivalent slopes during constant uphill and downhill running. For the latter, EE at various inclines is known so EE can be estimated based on incline [10]. This allows for the estimation of EE based on equivalent slopes, thus acceleration. Detailed descriptions of this method were provided in previous publications $[9,35,36]$.

\subsection{Statistical Analysis}

All statistical analyses were performed using SPSS ver. 18.0 (SPSS Inc., Chicago, IL, USA) with significance set at $p<0.05$ for all tests. Means \pm standard deviations across participants were calculated for descriptive statistics. Normal distribution affirmed via Shapiro-Wilk test was found for all used variables. Dependent-samples $t$-tests assessed differences in EE between the two different measuring systems. Effect size ( $\left.\eta^{2}\right)$ was used to estimate the magnitude of differences as follows: small ( $\left.\eta^{2} \geq 0.01\right)$, medium $\left(\mathrm{p} \eta^{2} \geq 0.06\right)$, and large $\left(\mathrm{p} \eta^{2} \geq 0.14\right)$ [37]. Pearson correlation coefficients $(r)$ were calculated and interpreted as: low $(r<0.5)$, moderate $(0.5 \leq r \leq 0.8)$, and high $(r>0.8)$ [37]. Regression models were developed to predict $\mathrm{EE}_{\text {Spiro }}$ based on $\mathrm{EE}_{\mathrm{LPM}}$. The same analyses were conducted for every single heat.

\section{Results}

$\mathrm{EE}_{\text {Spiro }}$ and $\mathrm{EE}_{\mathrm{LPM}}$ are presented in Table 1. For the entire test duration, a highly significant difference between $\mathrm{EE}_{\text {Spiro }}$ and $\mathrm{EE}_{\mathrm{LPM}}$ was found $(t(10)=19.94, p<0.001$, $\left.\mathrm{p} \eta^{2}=0.98\right)$. However, a significant correlation could not be determined $(r=0.32, p=0.34)$ 
(Figure 2A). All single heats differed between $\mathrm{EE}_{\text {Spiro }}$ and $\mathrm{EE}_{\mathrm{LPM}}(15.86 \leq t(10) \leq 19.35$, $\left.p<0.001, \mathrm{p} \eta^{2}=0.97\right)$, and no heat showed a significant correlation between the systems $(0.18 \leq p \leq 1, r \leq 0.44)$ (Table 2). As an example, heat \#6 $(r=0.26, p=0.46)$, the most intense heat of the GBPT, is shown in Figure $2 \mathrm{~B}$. Mean $\mathrm{EE}_{\text {Spiro }}$ and $\mathrm{EE}_{\mathrm{LPM}}$ during single heats are presented in Table 3. A visual comparison of both systems' data sets during the entire test duration is displayed in Figure 3. Individual values of REE as well as of pre-activated motionless EE in relation to gross EE are presented in Table 1. Subtracting REE from gross $\mathrm{EE}_{\text {Spiro }}$ did not affect the results of difference analysis $\left(t(10)=18.71, p<0.001, \mathrm{p} \eta^{2}=0.97\right)$ and correlation $(r=0.32, p=0.33)$. The high values of the pre-activated motionless EE (see Table 1) are not suitable for subtraction from $\mathrm{EE}_{\text {Spiro }}$ because of their magnitude (86.5 $\pm 7.8 \%$ of the gross EE across all participants, $100 \%$ of the gross EE for one participant). They were not used for further analyses.

Table 1. Energy expenditure (EE) via spiroergometry $\left(\mathrm{EE}_{\text {Spiro }}\right)$ and local position measurement ( $\left.\mathrm{EE}_{\mathrm{LPM}}\right)$ during the entire GBPT.

\begin{tabular}{|c|c|c|c|c|c|c|c|c|c|c|c|c|}
\hline & & \multicolumn{11}{|c|}{ Participants } \\
\hline & & P01 & P02 & P03 & P04 & P05 & P06 & P07 & P08 & P09 & P10 & P11 \\
\hline \multicolumn{13}{|l|}{ EE $_{\text {Spiro }}$} \\
\hline & {$[\mathrm{kJ} / \mathrm{kg} / \mathrm{min}]$} & 0.86 & 0.83 & 0.74 & 0.82 & 0.85 & 0.69 & 0.74 & 0.77 & 0.92 & 0.61 & 0.72 \\
\hline & {$[\mathrm{kJ} / \mathrm{min}]$} & 60.18 & 60.30 & 52.28 & 64.93 & 65.59 & 55.89 & 51.72 & 54.01 & 63.32 & 59.72 & 64.00 \\
\hline & {$[\mathrm{kcal} / \mathrm{min}]$} & 14.38 & 14.41 & 12.50 & 15.52 & 15.68 & 13.36 & 12.36 & 12.91 & 15.31 & 14.27 & 15.30 \\
\hline \multicolumn{13}{|l|}{ Resting EE } \\
\hline & {$[\mathrm{kJ} / \mathrm{kg} / \mathrm{min}]$} & 0.06 & 0.06 & 0.06 & 0.05 & 0.05 & 0.05 & 0.06 & 0.06 & 0.06 & 0.04 & 0.05 \\
\hline \multicolumn{13}{|c|}{ Pre-activated, motionless, resting EE } \\
\hline & {$[\mathrm{kJ} / \mathrm{kg} / \mathrm{min}]$} & 0.71 & 0.69 & 0.60 & 0.77 & 0.81 & 0.69 & 0.64 & 0.72 & 0.72 & 0.47 & 0.58 \\
\hline \multicolumn{13}{|c|}{$\mathrm{EE}_{\text {Spiro }}$ subtracted by resting EE } \\
\hline & {$[\mathrm{kJ} / \mathrm{kg} / \mathrm{min}]$} & 0.81 & 0.78 & 0.69 & 0.77 & 0.80 & 0.64 & 0.68 & 0.72 & 0.87 & 0.57 & 0.67 \\
\hline & {$[\mathrm{kJ} / \mathrm{min}]$} & 56.18 & 56.30 & 48.28 & 60.93 & 61.59 & 51.89 & 47.72 & 50.01 & 59.32 & 55.72 & 60.00 \\
\hline & {$[\mathrm{kcal} / \mathrm{min}]$} & 13.43 & 13.46 & 11.54 & 14.56 & 14.72 & 12.40 & 11.41 & 11.95 & 14.18 & 13.32 & 14.34 \\
\hline \multicolumn{13}{|l|}{$\mathrm{EE}_{\mathrm{LPM}}$} \\
\hline & {$[\mathrm{kJ} / \mathrm{kg} / \mathrm{min}]$} & 0.26 & 0.31 & 0.26 & 0.25 & 0.24 & 0.20 & 0.27 & 0.27 & 0.30 & 0.27 & 0.30 \\
\hline & {$[\mathrm{kJ} / \mathrm{min}]$} & 18.30 & 22.32 & 18.51 & 20.01 & 18.58 & 16.39 & 18.60 & 18.87 & 20.89 & 26.21 & 26.36 \\
\hline & {$[\mathrm{kcal} / \mathrm{min}]$} & 4.37 & 5.33 & 4.42 & 4.78 & 4.44 & 3.92 & 4.45 & 4.51 & 4.99 & 6.26 & 6.30 \\
\hline
\end{tabular}
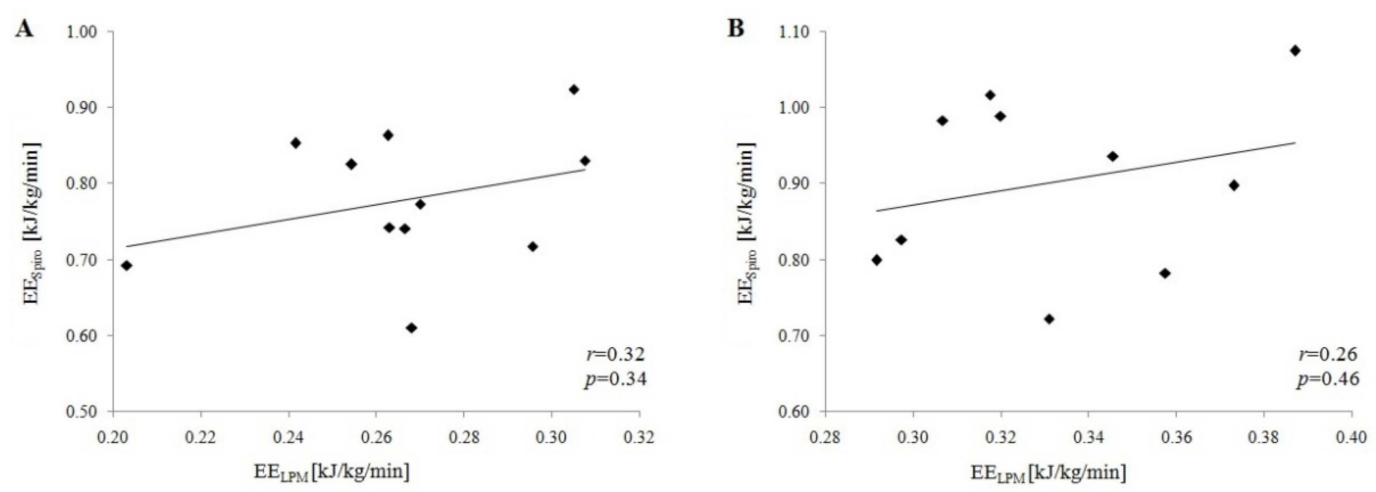

Figure 2. Correlation coefficient $(r)$ and significance $(p)$ between energy expenditure via spiroergometry $\left(E_{\text {Spiro }}\right)$ and via local position measurement system $\left(E_{L P M}\right)$ for the entire test $(A)$ and heat \#6 as an example for the most intensive heat $(\mathbf{B})$. 
Table 2. Pearson correlation coefficients $(r)$ and significance level $(p)$ between energy expenditure via spiroergometry and via local position measurement system for the entire test and every single heat (H1-H8).

\begin{tabular}{cccccccccccc}
\hline & Entire Test & H1 & H2 & H3 & H4 & H5 & H6 & H7 & H8 \\
\hline$r$ & 0.32 & 0 & 0.26 & 0.33 & 0.44 & 0.15 & 0.26 & 0.16 & 0.25 \\
$p$ & 0.34 & 1 & 0.43 & 0.33 & 0.18 & 0.69 & 0.46 & 0.66 & 0.49 \\
\hline
\end{tabular}

Table 3. Mean ( \pm standard deviation) energy expenditure $[\mathrm{kJ} / \mathrm{kg} / \mathrm{min}]$ via spiroergometry (EE $\mathrm{E}_{\text {Spiro }}$ ) and via local position measurement $\left(\mathrm{EE}_{\mathrm{LPM}}\right)$ of all participants for each heat $(\mathrm{H} 1-\mathrm{H} 8)$.

\begin{tabular}{ccccccccc}
\hline & H1 & H2 & H3 & H4 & H5 & H6 & H7 & H8 \\
\hline EE $_{\text {Spiro }}$ & $0.79 \pm 0.09$ & $0.89 \pm 0.12$ & $0.90 \pm 0.12$ & $0.89 \pm 0.11$ & $0.81 \pm 0.11$ & $0.90 \pm 0.12$ & $0.82 \pm 0.11$ & $0.80 \pm 0.09$ \\
EE $_{\text {LPM }}$ & $0.25 \pm 0.03$ & $0.28 \pm 0.03$ & $0.33 \pm 0.04$ & $0.32 \pm 0.05$ & $0.28 \pm 0.04$ & $0.33 \pm 0.03$ & $0.28 \pm 0.03$ & $0.30 \pm 0.05$ \\
\hline
\end{tabular}

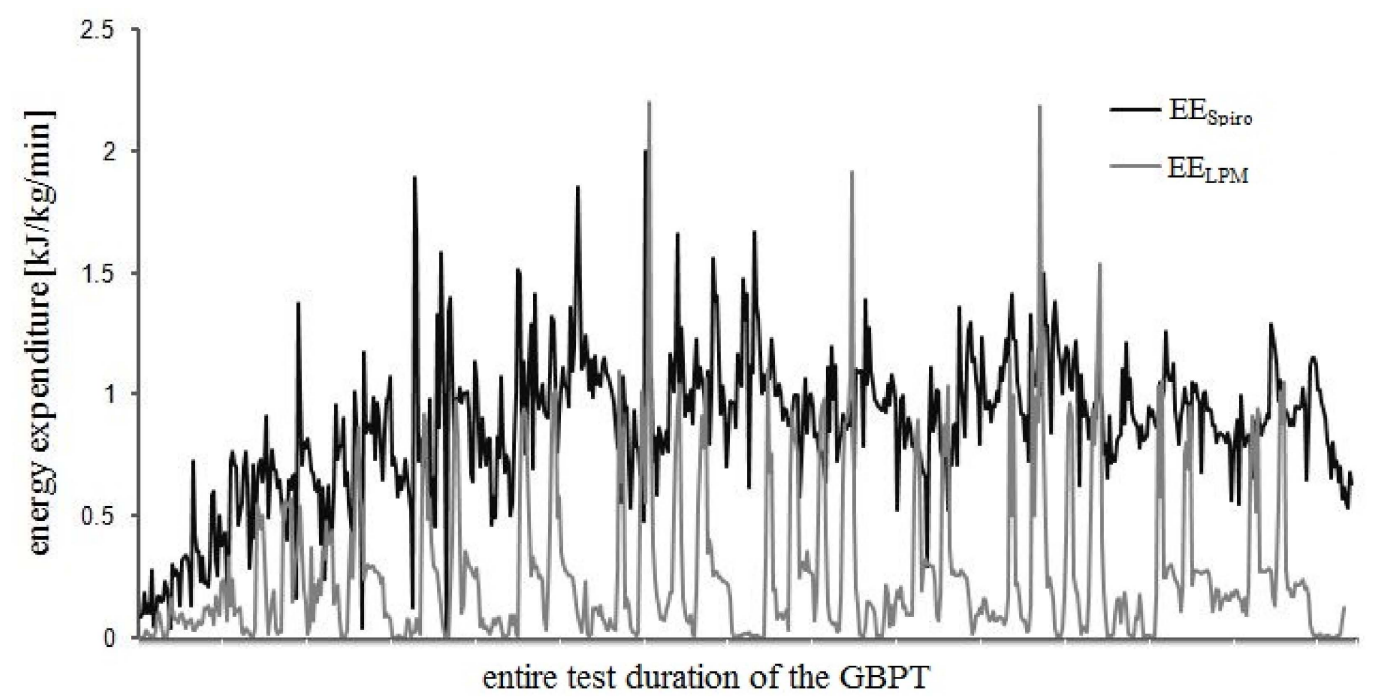

Figure 3. Energy expenditure via spiroergometry $\left(E_{S p i r o}\right)$ and via local position measurement $\left(\mathrm{EE}_{\mathrm{LPM}}\right)$ of the entire game-based performance test (GBPT) of one participant (P01).

\section{Discussion}

The first objective of the study was to analyze differences between $\mathrm{EE}_{\mathrm{Spiro}}$ and $\mathrm{EE}_{\mathrm{LPM}}$ during the team handball GBPT. As hypothesized, $\mathrm{EE}_{\text {Spiro }}$ was greater compared to $\mathrm{EE}_{\mathrm{LPM}}$ during the entire test and all single heats. One explanation is that the metabolic power method [9] estimates EE for locomotion only on horizontal acceleration and not correctly for non-locomotive actions (e.g., passes, throws) and other movements (e.g., tackles, jumps) [13].

The second objective was to analyze the correlation between $\mathrm{EE}_{\text {Spiro }}$ and $\mathrm{EE}_{\mathrm{LPM}}$. Correlation results for the entire test and all single heats were not significant $(0.18 \leq p \leq 0.99)$, with small correlation coefficients $(r \leq 0.44)$. As previously explained, we suggest that a relatively large part (e.g., passes, throws, tackles, and jumps) of the total EE was undetected by the LPM system (shown by the difference between $E_{\text {Spiro }}$ and $E_{L P M}$ ) and that this undetected $\mathrm{EE}$ in the $\mathrm{EE}_{\mathrm{LPM}}$ was not systematic. This was similar in all heats and therefore independent of inter-heat variations in movements and intensities.

The third objective was to develop a regression model that predicts EE Spiro $_{\text {based on }}$ $\mathrm{EE}_{\mathrm{LPM}}$. This regression model may have the potential to use the more practicable LPM system and the metabolic power model for EE [9] instead of the impractical spiroergometry (the gold standard). The results have shown that the regression analyses were not feasible.

The fourth objective was to investigate the REE compared with the EE during a pre-activated motionless rest for the estimation of net $\mathrm{EE}_{\text {Spiro. }}$ REE was very small 
$\left(6.8 \pm 0.6 \%\right.$ of the gross $\left.\mathrm{EE}_{\text {Spiro }}\right)$ and the subtraction of REE did not affect the statistical results (difference and correlation analyses for the entire test and all single heats). We suggest that REE affects the underestimation of $\mathrm{EE}_{\mathrm{LPM}}$ in comparison with $\mathrm{EE}_{\text {Spiro }}$ only to a limited degree. For an accurate comparison of $\mathrm{EE}_{\mathrm{LPM}}$ and $\mathrm{EE}_{\mathrm{Spiro}}$, $\mathrm{EE}$ during a preactivated, motionless rest would be the more meaningful factor than REE, because the metabolic power method cannot estimate the increased EE for the internal processes in a pre-activated state. However, it seemed that the EE in the pre-activated, motionless rest were affected by EPOC after warm-up, because the EE exceeded common values during standing. A total of $86.5 \pm 7.8 \%$ of the gross $\mathrm{EE}_{\text {Spiro }}$ across participants hardly represent valid EE for the pre-activated, motionless rest, and were therefore not subtracted for further analyses. The effect of additional EE during a pre-activated, motionless rest and potential EPOC after warm-up was also seen in an increased $\mathrm{EE}_{\text {Spiro }}$ at the beginning of the GBPT (Figure 3).

To compare the results in EE in the current study with previous studies during the various tasks at different intensity levels [32], the EE results were also presented as $\mathrm{kJ} / \mathrm{min}$ (see Table 1$)$. Intensity levels were classified as very light $(12-20 \mathrm{~kJ} / \mathrm{min})$, light (20-28 kJ/min), moderate (28-36 kJ/min), exhausting (36-52 kJ/min), and very exhausting ( $>52 \mathrm{~kJ} / \mathrm{min}$ ) [32]. According to this classification, the $\mathrm{EE}_{\text {Spiro }}$ during the GBPT was defined as 'very exhausting'. This is in line with previous results on perceived exhaustion after performing the GBPT ( $8.6 \pm 0.8$ on a scale of $1-10,10$ being total exhaustion) [19]. Another study corroborated the exhausting nature of the GBPT by a blood lactate concentration of $9.9 \pm 1.5 \mathrm{mmol} / \mathrm{L}$ for female and $8.7 \pm 1.6 \mathrm{mmol} / \mathrm{L}$ for male elite team-handball players [38]. The agreement in the intensity level of the current $\mathrm{EE}_{\text {Spiro }}$ with these previous findings supports the accuracy of the current $\mathrm{EE}_{\mathrm{Spiro}}$. In contrast, the current $\mathrm{EE}_{\mathrm{LPM}}$ $(20.46 \pm 3.26 \mathrm{~kJ} / \mathrm{min})$ was around the threshold between 'very light' and 'light', which is comparable with walking. This discrepancy with the simultaneously determined $\mathrm{EE}_{\text {Spiro, }}$ reported blood lactate levels [38], and perceived exhaustion [19] demonstrated that the $\mathrm{EE}_{\mathrm{LPM}}$ underestimated the EE dramatically. It is highly unlikely that the intensity level during the GBPT, a validated test that reflects the physical demands in team handball competition, performed by experienced athletes, is comparable with EE in walking. It should be considered that the intensity level refers to time-normalized EE and that the GBPT includes breaks (i.e., periods where $\mathrm{EE}_{\mathrm{LPM}}$ equals $0 \mathrm{~kJ}$, affecting the time-normalized EE) whereas the intensity classification refers to walking without breaks. This may explain the comparability between EE per minute during the GBPT and walking. Expecting that the $\mathrm{EE}_{\mathrm{LPM}}$ were estimated accurately in walking and running, the findings underline the great energetic contribution of team handball-specific actions (e.g., passing) and vertical displacements (e.g., jumps) to the total EE in team handball.

To exclude another potential challenge, the authors point out that the valid range of acceleration values in the metabolic power model [9] for $E_{\mathrm{LPM}}$ estimation is limited to approximately $\pm 4.42 \mathrm{~m} / \mathrm{s}^{2}$. Exceeding this range of $\pm 4.42 \mathrm{~m} / \mathrm{s}^{2}$ could lead to estimation errors [22]. However, in the present study, the accelerations and decelerations exceeded the valid range only in $0.03 \pm 0.06 \%$ of the total test duration. For all participants in the present study the maximum in deceleration was $-4.84 \mathrm{~m} / \mathrm{s}^{2}$ and in acceleration $5.01 \mathrm{~m} / \mathrm{s}^{2}$. Therefore, we conclude that the acceleration range in the calculation of $\mathrm{EE}_{\mathrm{LPM}}$ was no limitation.

The differences between $\mathrm{EE}_{\text {Spiro }}$ and $\mathrm{EE}_{\mathrm{LPM}}$ are in agreement with previous studies in team sports [11-13]. In the present study, we found a smaller EE of $-66 \pm 12 \%$ in $\mathrm{EE}_{\mathrm{LPM}}$ compared with gross $\mathrm{EE}_{\text {Spiro }}$ and $-63 \pm 12 \%$ compared with net $\mathrm{EE}_{\text {Spiro }}$ (after subtraction of REE). Similarly, EE LPM was $-54 \pm 9 \%$ smaller in soccer using a comparable test design of a soccer-specific circuit test [12]. In test designs with reduced specificity (incremental treadmill running), the underestimation of $\mathrm{EE}_{\mathrm{LPM}}$ compared to $\mathrm{EE}_{\text {Spiro }}$ was much smaller $(-13$ to $-16 \%)$ [8]. Another aspect is the involvement of the ball because it was found that $\mathrm{EE}_{\text {Spiro }}$ increased by $9 \%$ when involving a ball, whereas $\mathrm{EE}_{\mathrm{LPM}}$ increased only by $1 \%$ [7]. We suggest that the difference between $\mathrm{EE}_{\mathrm{LPM}}$ and $\mathrm{EE}_{\text {Spiro }}$ increases with more 
specificity; consequently, the sport-specific actions play a major role in the estimation of EE in team sports.

Physical collisions were another explanation for the difference between $\mathrm{EE}_{\mathrm{LPM}}$ and $\mathrm{EE}_{\text {Spiro }}$ in collision-based activities in rugby [13]. It was found that $\mathrm{E}_{\mathrm{LPM}}$ was reduced by $-45 \pm 17 \%$ due to physical collisions [13]. However, physical collisions cannot be the only explanation for the systematic underestimation in $\mathrm{EE}_{\mathrm{LPM}}$, because in soccer similar results were found, although the study has included no physical collisions [8,12]. Different results in $\mathrm{EE}_{\mathrm{LPM}}$ compared with $\mathrm{EE}_{\text {Spiro }}$ were also found between game sport-specific movement patterns $(-44 \%)$, fast running $(4.8 \%)$, moderate running $(7.8 \%)$, and walking $(43 \%)$ [11]. EE $E_{L P M}$ was underestimated in sport-specific movements and overestimated in non-specific locomotion. It seems that slower locomotion increased the overestimation of $\mathrm{EE}_{\mathrm{LPM}}$. However, regarding the overestimation of $\mathrm{EE}_{\mathrm{LPM}}$ for walking, the $\mathrm{EE}_{\mathrm{LPM}}$ calculation model was adapted for running [36].

Potential sources of errors can be summarized as vertical movements like jumps, which cannot be identified in horizontal position data, typical game sports actions like shots [12], ball control during running [7], and collisions [13]. Additional errors must be expected as they were documented also in a shuttle-run test without any of the aforementioned actions [8].

Therefore, limitations of the study included a variety of potential sources of errors in the LPM system, which have been outlined and discussed in previous sections. These were challenges observed in the current as well as previous studies in calculating the EE via position-measuring systems. Another limitation is that a comparison within the sample (e.g., sex) was not feasible due to the small sample size. However, a strength and practical implication of the study is that the results of the current study can help to advance the metabolic power model for $\mathrm{EE}$, which has a huge potential because of its applicability in team sport competition as well as to prevent incorrect application of the method. In the present study, we have not found a valid regression model to predict $\mathrm{EE}_{\text {Spiro }}$ by $\mathrm{EE}_{\mathrm{LPM}}$, to improve the accuracy of $E_{\mathrm{LPM}}$. However, future studies are warranted to successfully develop more complex models by identifying and integrating the most relevant error factors (e.g., occurrence of sports-specific actions).

\section{Conclusions}

The estimation of $\mathrm{EE}_{\mathrm{LPM}}$ via player position data has the potential to overcome practical limitations of the gold standard method to determine EE (indirect calorimetry) and can be applied in team sports training and competition for all players simultaneously. However, reduced accuracy, especially with increasing sports-specific movements, is the key weakness in determining $E_{\mathrm{LPM}}$. $\mathrm{E}_{\mathrm{LPM}}$ was greatly underestimated during the team handball GBPT in comparison with valid $\mathrm{EE}_{\text {Spiro }}$. Because of poor correlation, regression models could not be developed to predict the more accurate $\mathrm{EE}_{\text {Spiro }}$ based on the more practical $\mathrm{EE}_{\mathrm{LPM}}$. At the current stage, the accuracy of $\mathrm{EE}_{\mathrm{LPM}}$ is not sufficient to determine the $\mathrm{EE}$ in team handball. In settings where spiroergometry is feasible (e.g., laboratory or testing) this seems to be the preferred method for energy estimations. In other settings, where this is not feasible (e.g., in competition) the approach via LPM may be alternatively used but should be interpreted with caution. These findings are relevant for future application and interpretation of $\mathrm{EE}_{\mathrm{LPM}}$ in team handball and may encourage further development of measurement and estimation methods.

Author Contributions: Conceptualization, P.F. and H.W.; methodology, P.F., P.X.F. and H.W.; formal analysis, P.F., L.S.L. and H.W.; investigation, P.F., L.S.L. and H.W.; resources, L.S.L. and H.W.; data curation, P.F. and L.S.L.; writing-original draft preparation, P.F.; writing-review and editing, P.F, L.S.L., P.X.F. and H.W.; visualization, P.F. and H.W.; supervision, H.W.; project administration, H.W. All authors have read and agreed to the published version of the manuscript.

Funding: This research received no external funding. 
Institutional Review Board Statement: The study was conducted according to the guidelines of the Declaration of Helsinki and approved by the Ethics Committee of The Norwegian School of Sport Sciences (protocol code: 117-241019 and date of approval: 16 October 2019).

Informed Consent Statement: Informed consent was obtained from all subjects involved in the study.

Data Availability Statement: The data presented in this study are available on request from the authors. The data are not publicly available due to data protection rules of the University of Salzburg.

Acknowledgments: The authors would like to thank Håkon Laugsand from the Department of Physical Performance, Norwegian School of Sport Sciences for his skillful assistance during data collection as well as all athletes for their participation and great effort.

Conflicts of Interest: The authors declare no conflict of interest.

\section{References}

1. Oliva-Lozano, J.M.; Muyor, J.M.; Fortes, V.; McLaren, S.J. Decomposing the variability of match physical performance in professional soccer: Implications for monitoring individuals. Eur. J. Sport Sci. 2020, 21, 1588-1596. [CrossRef]

2. Debien, P.; Mancini, M.; Coimbra, D.R.; De Freitas, D.G.; Miranda, R.; Filho, M.G.B. Monitoring Training Load, Recovery, and Performance of Brazilian Professional Volleyball Players during a Season. Int. J. Sports Physiol. Perform. 2018, 13, 1182-1189. [CrossRef] [PubMed]

3. Wik, E.H.; Luteberget, L.S.; Spencer, M. Activity Profiles in International Women's Team Handball Using PlayerLoad. Int. J. Sports Physiol. Perform. 2017, 12, 934-942. [CrossRef]

4. Hoogkamer, W.; Kipp, S.; Frank, J.H.; Farina, E.M.; Luo, G.; Kram, R. A Comparison of the Energetic Cost of Running in Marathon Racing Shoes. Sports Med. 2018, 48, 1009-1019. [CrossRef] [PubMed]

5. Mady, C.E.K.; Igarashi, T.L.; Albuquerque, C.; Santos-Silva, P.R.; Fernandes, T.L.; Hernandez, A.J. Exergy efficiency on incremental stationary bicycle test: A new indicator of exercise performance? J. Braz. Soc. Mech. Sci. Eng. 2019, 41, 566. [CrossRef]

6. Polglaze, T.; Hoppe, M.W. Metabolic Power: A Step in the Right Direction for Team Sports. Int. J. Sports Physiol. Perform. 2019, 14, 407-411. [CrossRef]

7. Piras, A.; Raffi, M.; Atmatzidis, C.; Merni, F.; Di Michele, R. The Energy Cost of Running with the Ball in Soccer. Int. J. Sports Med. 2017, 38, 877-822. [CrossRef] [PubMed]

8. Stevens, T.G.A.; DE Ruiter, C.J.; VAN Maurik, D.; VAN Lierop, C.J.W.; Savelsbergh, G.J.P.; Beek, P.J. Measured and Estimated Energy Cost of Constant and Shuttle Running in Soccer Players. Med. Sci. Sports Exerc. 2015, 47, 1219-1224. [CrossRef]

9. Di Prampero, P.E.; Fusi, S.; Sepulcri, L.; Morin, J.-B.; Belli, A.; Antonutto, G. Sprint running: A new energetic approach. J. Exp. Biol. 2005, 208, 2809-2816. [CrossRef]

10. Minetti, A.E.; Moia, C.; Roi, G.S.; Susta, D.; Ferretti, G. Energy cost of walking and running at extreme uphill and downhill slopes. J. Appl. Physiol. 2002, 93, 1039-1046. [CrossRef]

11. Brown, D.M.; Dwyer, D.B.; Robertson, S.J.; Gastin, P.B. Metabolic Power Method: Underestimation of Energy Expenditure in Field-Sport Movements Using a Global Positioning System Tracking System. Int. J. Sports Physiol. Perform. 2016, 11, 1067-1073. [CrossRef]

12. Buchheit, M.; Manouvrier, C.; Cassirame, J.; Morin, J.-B. Monitoring Locomotor Load in Soccer: Is Metabolic Power, Powerful? Int. J. Sports Med. 2015, 36, 1149-1155. [CrossRef] [PubMed]

13. Highton, J.; Mullen, T.; Norris, J.; Oxendale, C.; Twist, C. The Unsuitability of Energy Expenditure Derived From Microtechnology for Assessing Internal Load in Collision-Based Activities. Int. J. Sports Physiol. Perform. 2017, 12, 264-267. [CrossRef]

14. Luteberget, L.S.; Spencer, M. High-Intensity Events in International Women's Team Handball Matches. Int. J. Sports Physiol. Perform. 2017, 12, 56-61. [CrossRef]

15. Michalsik, L.B.; Aagaard, P.; Madsen, K. Technical Activity Profile and Influence of Body Anthropometry on Playing Performance in Female Elite Team Handball. J. Strength Cond. Res. 2015, 29, 1126-1138. [CrossRef] [PubMed]

16. Michalsik, L.B.; Madsen, K.; Aagaard, P. Match Performance and Physiological Capacity of Female Elite Team Handball Players. Int. J. Sports Med. 2013, 35, 595-607. [CrossRef]

17. Michalsik, L.B.; Aagaard, P.; Madsen, K. Locomotion Characteristics and Match-Induced Impairments in Physical Performance in Male Elite Team Handball Players. Int. J. Sports Med. 2012, 34, 590-599. [CrossRef]

18. Buchheit, M.; Lepretre, P.; Behaegel, A.; Millet, G.; Cuvelier, G.; Ahmaidi, S. Cardiorespiratory responses during running and sport-specific exercises in handball players. J. Sci. Med. Sport 2009, 12, 399-405. [CrossRef]

19. Wagner, H.; Orwat, M.; Hinz, M.; Pfusterschmied, J.; Bacharach, D.W.; von Duvillard, S.P.; Müller, E. Testing Game-Based Performance in Team-Handball. J. Strength Cond. Res. 2016, 30, 2794-2801. [CrossRef] [PubMed]

20. Buglione, A.; di Prampero, P.E. The energy cost of shuttle running. Eur. J. Appl. Physiol. 2013, 113, 1535-1543. [CrossRef]

21. Buchheit, M.; Simpson, B.M. Player-Tracking Technology: Half-Full or Half-Empty Glass? Int. J. Sports Physiol. Perform. 2017, 12 (Suppl. S2), S2-S35. [CrossRef]

22. Osgnach, C.; Paolini, E.; Roberti, V.; Vettor, M.; di Prampero, P.E. Metabolic Power and Oxygen Consumption in Team Sports: A Brief Response to Buchheit et al. Int. J. Sports Med. 2016, 37, 77-81. [CrossRef] [PubMed] 
23. Panissa, V.L.G.; Fukuda, D.H.; Staibano, V.; Marques, M.; Franchini, E. Magnitude and duration of excess of post-exercise oxygen consumption between high-intensity interval and moderate-intensity continuous exercise: A systematic review. Obes. Rev. 2020, 22, 13099. [CrossRef]

24. Arney, B.E.; Foster, C.; Porcari, J. EPOC: Is it real? Does it matter? ACSM's Health Fit. J. 2019, 23, 9-13. [CrossRef]

25. Michalsik, L.B.; Madsen, K.; Aagaard, P. Physiological capacity and physical testing in male elite team handball. J. Sports Med. Phys. Fit. 2015, 55, 415-429.

26. Michalsik, L.B.; Madsen, K.; Aagaard, P. Technical Match Characteristics and Influence of Body Anthropometry on Playing Performance in Male Elite Team Handball. J. Strength Cond. Res. 2015, 29, 416-428. [CrossRef]

27. Michalsik, L.B.; Aagaard, P. Physical demands in elite team handball: Comparisons between male and female players. J. Sports Med. Phys. Fit. 2014, 55, 878-891.

28. Wagner, H.; Fuchs, P.X.; Von Duvillard, S.P. Specific physiological and biomechanical performance in elite, sub-elite and in non-elite male team handball players. J. Sports Med. Phys. Fit. 2018, 58, 73-81. [CrossRef] [PubMed]

29. Perez-Suarez, I.; Martin-Rincon, M.; Henríquez, J.J.G.; Fezzardi, C.; Perez-Regalado, S.; Galvan-Alvarez, V.; Juan-Habib, J.W.; Morales-Alamo, D.; Calbet, J.A.L. Accuracy and Precision of the COSMED K5 Portable Analyser. Front. Physiol. 2018, 9, 1764. [CrossRef]

30. Guidetti, L.; Meucci, M.; Bolletta, F.; Emerenziani, G.P.; Gallotta, M.C.; Baldari, C. Validity, reliability and minimum detectable change of COSMED K5 portable gas exchange system in breath-by-breath mode. PLoS ONE 2018, 13, e0209925. [CrossRef]

31. Brockway, J.M. Derivation of formulae used to calculate energy expenditure in man. Hum. Nutr. Clin. Nutr. 1987, 41, 463-471. [PubMed]

32. Jeukendrup, A.; Gleeson, M. Sport Nutrition: An Introduction to Energy Production and Performance; Human Kinetics: Champaign, IL, USA, 2004.

33. Serpiello, F.R.; Hopkins, W.G.; Barnes, S.; Tavrou, J.; Duthie, G.M.; Aughey, R.J.; Ball, K. Validity of an ultra-wideband local positioning system to measure locomotion in indoor sports. J. Sports Sci. 2018, 36, 1727-1733. [CrossRef]

34. Luteberget, L.S.; Spencer, M.; Gilgien, M. Validity of the Catapult ClearSky T6 Local Positioning System for Team Sports Specific Drills, in Indoor Conditions. Front. Physiol. 2018, 9, 115. [CrossRef] [PubMed]

35. Osgnach, C.; Poser, S.; Bernardini, R.; Rinaldo, R.; DI Prampero, P.E. Energy Cost and Metabolic Power in Elite Soccer: A new match analysis approach. Med. Sci. Sports Exerc. 2010, 42, 170-178. [CrossRef]

36. Di Prampero, P.E.; Osgnach, C. Metabolic Power in Team Sports-Part 1: An Update. Int. J. Sports Med. 2018, $39,581-587$. [CrossRef] [PubMed]

37. Cohen, J. Statistical Power Analysis for the Behavioral Sciences, 2nd ed.; Lawrence Erlbaum Associates: New York, NY, USA, 1988.

38. Wagner, H.; Fuchs, P.; Fusco, A.; Fuchs, P.X.; Bell, J.W.; Von Duvillard, S.P. Physical Performance in Elite Male and Female Team-Handball Players. Int. J. Sports Physiol. Perform. 2019, 14, 60-67. [CrossRef] [PubMed] 